\title{
Correspondence
}

\section{Inadvertent insertion of a gastric tube into the airway in an awake patient}

To the Editor:

A fit and healthy 69-yr-old man, height $167 \mathrm{~cm}$, weight $58 \mathrm{~kg}$, was scheduled for cholecystectomy. Diazepam $5 \mathrm{mg}$ was given orally as premedication and about two hours later, a surgeon inserted a 16-Fr nasogastric tube and encouraged the patient to swallow while advancing the tube until the $50-\mathrm{cm}$ mark was at the naris. The patient, who was awake, coughed several times during insertion, but coughing subsided spontaneously. The surgeon did not confirm the position of the tube and sent the patient to the operating theatre, where the patient was placed in the left decubitus position for insertion of an epidural catheter. The patient coughed mildly every few minutes, and claimed that he felt irritation in the back of the throat due to the gastric tube. At laryngoscopy after induction of anesthesia, we found that the gastric tube was inserted inside the trachea. The "gastric" tube was removed and an endotracheal tube inserted. The operation proceeded uneventfully and no airway complications occurred postoperatively.

There have been more than 50 reports of inadvertent insertion of a large-bore or small-bore gastrointestinal tube into the airway. Some patients reported were awake, but all of them were neurologically impaired, ${ }^{1}$ critically ill ${ }^{2}$ or had depressed respiratory responses. ${ }^{3}$ In our case, the patient was conscious (although $5 \mathrm{mg}$ diazepam was given orally), had no pathological changes of the respiratory and alimentary tracts, and the symptoms were mild despite the presence of a large-bore nasogastric tube in the airway. This case indicates that inadvertent tracheal insertion of a gastric tube may go unnoticed, even in healthy adults. In addition, conventional confirmatory methods, such as auscultation of the epigastrium during insufflation of air into the tube or aspiration of fluid through a tube, may not detect inadvertent airway insertion. Therefore, more reliable methods such as absence of capnography through a tube, ${ }^{4,5}$ should also be used to confirm the position of the gastric tube even in unimpaired patients, specially before infusion of any fluid (such as for preoperative gastric lavage).
Takashi Asai MD PhD

Osaka, Japan

Ikuhiro Hidaka MD

Shoji Kawachi MD

Shimane, Japan

References

1 Harvey PB, Bull PT, Harris DL. Accidental intrapulmonary Clinifeed. Anaesthesia 1981; 36: $518-22$.

2 Olbrantz KR, Gelfand D, Choplin R, Wu WC. Pneumothorax complicating enteral feeding tube placement. JPEN Parenter Enteral Nutr 1985; 9: 210-1.

3 Torrington KG, Bowman MA. Fatal hydrothorax and empyema complicating a malpositioned nasogastric tube. Chest 1981; 79: 240-2.

4 Asai T, Stacey M. Confirmation of feeding tube position; how about capnography? Anaesthesia 1994; 49: 451 .

5 Kindop AS, Drover JW, Heyland DK. Capnography confirms correct feeding tube placement in intensive care unit patients. Can J Anesth 2001; 48: 705-10.

\section{Unexpectedly low levels of plasma brain natriuretic peptide in the patient with massive pulmonary tumour emboli}

To the Editor:

Severe pulmonary tumour embolism is a very unusual disaster and leads to acute as well as chronic pulmonary hypertension. ${ }^{1}$ Brain natriuretic peptide (BNP) is mainly secreted from the cardiac ventricles and the plasma levels of BNP increase according to the extent of right ventricular dysfunction mediated by right ventricular overload, specially that induced by higher pulmonary arterial pressures. ${ }^{2}{ }^{3}$ Plasma levels of BNP have not been determined in severe pulmonary tumour emboli. We report the unexpectedly low perioperative levels of plasma BNP in a patient undergoing embolectomy for massive pulmonary tumour emboli.

A 57-yr-old male patient experienced right ventricular failure secondary to pulmonary arterial emboli. Echocardiogram showed right ventricular as well as 